\title{
Erratum zu: Terminologiemanagement
}

\section{Erratum to: \\ P. Drewer Klaus-Dirk Schmitz \\ Terminologiemanagement, https://doi.org/10.1007/ 978-3-662-53314-7}

der folgende Text wurde auf der Impressumseite (Titelei Seite IV) eingefügt:

„Konzeption der Reihe Kommunikation + Medienmanagement: Prof. Sissi Closs und Prof. Petra Drewer, Studiengang Kommunikation und Medienmanagement an der Hochschule Karlsruhe“

Die Online-Version des Originalbuches finden Sie unter https://doi.org/10.1007/978-3-662-53315-4

(C) Springer-Verlag GmbH Deutschland 2017

P. Drewer, K.-D. Schmitz, Terminologiemanagement,

Kommunikation und Medienmanagement,

https://doi.org/10.1007/978-3-662-53315-4_8 